\title{
Erratum to: The role of vocabulary depth in predicting reading comprehension among English monolingual and Spanish-English bilingual children in elementary school
}

\author{
C. Patrick Proctor • Rebecca D. Silverman • \\ Jeffrey R. Harring • Christine Montecillo
}

Published online: 1 December 2011

(C) Springer Science+Business Media B.V. 2011

\section{Erratum to: Read Writ \\ DOI 10.1007/s11145-011-9336-5}

Acknowledgment of the funder was omitted from the original publication of this article, and appears below:

\section{Acknowledgments}

The research reported here was funded by a grant from the Institute of Education Sciences, U.S. Department of Education, to the University of Maryland (No. R305A090152). The opinions expressed are those of the authors and do not represent views of the institute or the U.S. Department of Education.

The online version of the original article can be found under doi:10.1007/s11145-011-9336-5.

C. P. Proctor $(\bowtie) \cdot$ C. Montecillo

Department of Curriculum \& Instruction, Lynch School of Education, Boston College,

140 Commonwealth Ave., Chestnut Hill, MA 02467, USA

e-mail: proctoch@bc.edu

\section{R. D. Silverman}

Department of Special Education, University of Maryland, College Park, MD, USA

J. R. Harring

Department of Measurement, Statistics, \& Evaluation, University of Maryland, College Park, MD, USA 